\title{
Motivating provision of high quality care: it is not all about the money
}

\author{
Mylène Lagarde, Luis Huicho, and Irene Papanicolas discuss different strategies policy makers \\ can use to motivate health providers in order to improve quality of care
}

The inclusion of universal health coverage as a target in the sustainable development goal for health has boosted the global movement to improve access to healthcare services. To improve health, the services accessed must be high quality, ${ }^{1}$ yet there is mounting evidence that the quality of care delivered to populations in many low and middle income countries is inadequate..$^{2-5}$ Governments must consider strategies that will not only improve accessibility to care for their populations but also substantially improve quality.

A priority in achieving universal health coverage is the recruitment, training, and retention of healthcare workers. However, there is widespread concern that health systems are not getting the most out of their workforce. Recent evidence shows that the quality of care provided by healthcare workers is often lower than what they are able to demonstrate in the context of a test ${ }^{2}$ or under the watchful eyes of an observer. ${ }^{6}$ The existence of such "know-do" gaps shows that substandard care cannot be fully explained by low competence or inadequate training.

Low quality of care and medical errors occur more often when providers are demotivated, which can be fuelled by inadequate working conditions such as shortages of basic drugs and equipment or staff. ${ }^{7-9}$ Yet, although good working conditions are an important part of delivering good quality of care, they are not sufficient to ensure that health professionals are motivated and adhere to recommended treatment guidelines. ${ }^{1011}$ Here, we discuss the evidence

\section{REY MESSAGES}

- Policy makers need to look beyond traditional financial incentives when designing policies to improve care

- Health professionals are motivated by a range of factors, both extrinsic and intrinsic

- Incentives that focus on these other motivations or a combination may be more effective on different approaches that can be used to increase provider motivation and ultimately improve quality of care.

\section{Financial incentives are not always worth the investment}

Economists, managers, and policy makers have long seen remuneration as an obvious lever to influence providers' behaviour. In high income settings, the use of direct financial incentives to improve quality has been ubiquitous with the aim of maintaining high quality standards while encouraging more efficient spending. In settings where salaries are low and health workers demotivated, ${ }^{7}$ similar pay-for-performance schemes have been used, often to achieve a dual objective: to increase remuneration and to provide incentives for improving performance.

Despite the enthusiasm for these schemes, the evidence of their impact on quality of care is lacklustre. Although they have been found to increase adherence to quality of care processes, their overall effects are mixed and, when positive, small. ${ }^{12-14}$ For example, an experiment in Rwanda led to the improvement of some rewarded measures of process of care (eg, iron supplementation for children, urine analysis in antenatal care), but not of others (eg, malaria prophylaxis and tetanus vaccination for pregnant women), ${ }^{1516}$ and provider effort in antenatal consultations was only slightly higher than in the absence of incentives. ${ }^{17}$ This is one of several examples of the mixed results achieved by pay-for-performance schemes in terms of quality improvement in low income settings, which are disappointing considering the investment made. ${ }^{18}$

The global evidence is similarly mixed, with no evidence of significant improvement in health outcomes after the introduction of pay-for-performance schemes. ${ }^{13}$ Furthermore, caution is needed to avoid unintended consequences that can be costly or compromise quality. For example, when income is directly linked to drug sales, more unnecessary drugs are likely to be prescribed ${ }^{19}$; when providers are reimbursed differently for inputs with similar health benefits they may choose the more profitable ones at the expense of efficiency. ${ }^{20}$ More generally, questions remain about the cost effectiveness of using financial incentives, especially when budgets are tight. ${ }^{21}$

The multiple ways in which financial incentives can be designed, as well as the complexity of the healthcare environment in which they are introduced, ${ }^{22}$ may help explain why results have not always been as expected. ${ }^{23}$ Incentive schemes can differ in terms of the number and types of performance indicators targeted, the size of the reward in relation to provider's income, or the extent to which the performance targets are completely under a provider's control. All of these design choices matter and influence the effect of the incentives. ${ }^{24}$ The incentive will also be more powerful if it directly targets individual providers (specialists) rather than small teams (primary care centres) or large organisations (hospitals). If individuals value losses more than gains, penalties for failing to achieve targets will work better than rewards for doing so. ${ }^{25}$

Lastly, providers' personal characteristics may affect how they respond to incentives. For instance, a recent study found that certain personality traits may predispose some people to respond more to incentives than others. ${ }^{26}$ For people driven by factors other than remuneration, financial incentives may backfire. ${ }^{27}$ This may be particularly relevant to the healthcare sector, as workers are likely to care about not only their income but also their reputation, their patients, or their job.

\section{Reputation matters in some contexts}

Another way to incentivise quality improvement is to publish providers' performance to the public or to their peers. This approach harnesses the power of another source of extrinsic motivation, concerns for your reputation, which are expected to push individuals to perform better. ${ }^{25} 28$

Many countries have made measures of hospital performance publicly available, 
typically reporting on waiting times or patient experience, and sometimes on measures of quality and safety, such as mortality and complications. Most evidence on the impact of public reporting comes from the US and shows mixed results. ${ }^{29}$ For hospitals, public reporting has been linked to small increases in adherence to processes of care ${ }^{30}$ but not to reductions in mortality. ${ }^{3132}$ For individual health professionals, it has been associated with decreases in mortality, ${ }^{33}{ }^{34}$ but there are concerns about how these reductions are achieved, and in particular the extent to which public reporting encourages patient selection. $^{3536}$

In settings where administrative information on provider quality is lacking or less credible, public reporting of provider performance can rely on community based monitoring of service delivery and engagement with providers. ${ }^{37}$ Robust evidence on such initiatives is still limited, but in a pioneering experiment in Uganda, when non-governmental organisations distributed reports on use and quality of services to local communities, mortality in children under 5 years old fell by a third. ${ }^{38}$

Public reporting programmes could therefore be a worthwhile strategy to promote quality, but their effectiveness requires careful design and a favourable environment. $^{22}$ The information reported has to be credible and salient. To achieve this, it has to come from a trustworthy source; depending on the setting this may or may not be the government. ${ }^{39}$ Equally, the information reported has to be noticeable and focused on a few indicators, to avoid being ignored. ${ }^{40}$

Public reporting will improve quality only if providers are held accountable for their performance in some way. Even in the absence of potential reputational or legal consequences, publicly reporting poor practice can have financial consequences in a competitive healthcare market. If providers' income is linked to the volume of patients, low performers will be automatically penalised as patients will "vote with their feet" and choose higher quality providers. But to achieve this, patients must be able to both access and use the information reported. In many settings, this may require additional supporting initiatives to help patients navigate a complex environment, or simply use and interpret the data. Conversely, if poor practice does not lead to negative consequences for providers-whether financial, moral or legal-public reporting will be a toothless policy.

\section{Harnessing the power of intrinsic motivation}

Intrinsic motivation is known to be a powerful driver of provider behaviours. ${ }^{41-44}$ Two different sources of motivation are identified: the satisfaction derived from undertaking actions that benefit other people or society (sometimes referred to as altruistic or prosocial motivation) and the interest or enjoyment of a task itself.

Evidence is emerging that intrinsically motivated providers display desirable behaviours or attitudes towards patients. Health education research in high income countries shows the importance and long term benefits of selecting people with altruistic values, such as compassion or empathy, into the medical profession. ${ }^{45}$ Research in sub-Saharan Africa has found that nurses who are more generous towards patients are more likely to choose jobs in rural and remote areas, ${ }^{46}$ and that more generous clinicians provide better quality of care to patients. ${ }^{47}$ Yet, few interventions have rigorously explored the extent to which intrinsic motivation can be shaped or harnessed to motivate quality improvement.

Policy interventions that could appeal to this type of motivation fall into two categories, depending on whether intrinsic motivation is seen to be malleable or not. If intrinsic motivation is an innate individual trait, policy makers should try to select more people who display the right type of motivation. On the other hand, if intrinsic motivation is a form of capital that can be depreciated or accrued, ${ }^{48}$ specific interventions should be introduced to nurture it. We consider recent examples of both approaches.

\section{Selecting people with intrinsic motivation}

Many countries have introduced programmes to select people into medical or nursing training by introducing quotas based on people's geographical origin in order to increase the rural retention of staff, especially in low income settings, ${ }^{49} 50$ but selection of medical students is still mostly based on academic attainment. There are concerns that this approach is not sufficient to ensure that people with softer skills are selected. ${ }^{51} \mathrm{~A}$ few countries have started to introduce selection procedures to identify medical workers with personality traits and values indicative of intrinsic and altruistic motivation. ${ }^{52}$ However, such initiatives are still in their infancy, and controversy remains about the types of non-academic attributes that should be included and the validity of the selection procedures. More research needs to be carried out to determine which attributes are associated with better patient care for specific types of healthcare workers to inform such initiatives.

Selecting the "right" attributes is also critical when recruiting people for specific jobs. As economic theory suggests that people sort into jobs matching their preferences or motivation, ${ }^{535}$ employers could attract the "right" people by emphasising certain job characteristics. A non-governmental organisation recently tested this idea in Uganda, exploring whether highlighting particular aspects of the role of community health workers would make the job appeal to more altruistic people. ${ }^{55}$ Information about job remuneration was manipulated to suggest to applicants that the main role was either more commercial (selling small products such as salt or soap to households) or more prosocial (providing health advice). When lower remuneration was advertised, potential applicants inferred the social aspect of the job was more important; those who applied showed higher levels of altruism and ended up staying longer on the job and visited households more frequently. ${ }^{55}$ Similar success with framing job adverts has been found in other sectors, ${ }^{5657}$ and it deserves further exploration.

\section{Nurturing intrinsic motivation through feedback}

Few policies have sought to specifically influence or nurture the motivational capital of providers. Examples include encouraging quality improvement through educational outreach programmes or audit and feedback, either to promote the definition of shared quality norms among groups of providers, or to highlight the benefits of good quality for patients.

An example of such interventions are physician collaboratives, which have some positive effects on quality of care. ${ }^{58}$ This approach uses confidential performance feedback to individuals and then creates opportunities to share lessons in a multidisciplinary setting and agree on high quality standards and practices. The Swedish quality registers are often highlighted as an example that has had a sustained and large effect on quality. ${ }^{59}$ Crucial to their success seems to be the fact that they are not part of an external regulatory or performance management process, but that they are driven by physicians themselves, who have promoted a culture of constructive appraisal and commitment to quality. ${ }^{59}$

Whereas physician collaboratives highlight the importance of professional 
norms and expectations to foster intrinsic motivation, two other examples show how provider performance can be enhanced by nurturing the altruistic motivation of providers. The first comes from the US, where healthcare professionals in a hospital were more likely to change their behaviour and adopt better practices when a campaign for hand washing highlighted the benefits for patients rather than the benefit to themselves. ${ }^{60}$ The second comes from a low income setting, where altruistic motivation might be expected to have limited effects given the low remuneration and challenging working conditions. Yet, in a recent experiment in India, community health workers who received regular information highlighting the benefits they were creating for patients increased their performance by $25 \%$, and this effect was strongest for those with high levels of intrinsic and altruistic motivation. ${ }^{61}$ These examples highlight the need to identify policies that can preserve and nurture such reservoirs of goodwill.

\section{Improving provider motivation}

Not everyone is motivated in the same way, ${ }^{62}$ and the interventions that we have described should not be seen as mutually exclusive. Instead they form a palette of options from which policy makers can choose to design the most relevant solution. This process should start with a needs assessment to identify and understand the local obstacles that limit performance and undermine quality of care. In some settings, preliminary problems might have to be addressed before tackling low motivation. For example, if staff do not have the clinical skills to make a correct diagnosis, no amount of money or feedback will increase technical quality of care. If essential basic drugs and equipment are not available, incentives will not improve the treatments provided to patients.

In other contexts, careful consideration should be given to the broader environment in which health workers operate to understand their behaviour. Maslow's seminal motivation theory ${ }^{63}$ states that people seek to satisfy their most pressing physiological and safety needs before they can be influenced by "growth" needs such as reputational concerns or altruism. In other words, if their financial remuneration is insufficient for them to make ends meet, providers are likely to be predominantly driven by financial motives. However, satisfaction of needs is not an "all or nothing" phenomenon. ${ }^{64}$ Similarly, we have reinforced the importance of bearing in mind that health professionals are heterogeneous in their preferences and the relative weight they place on these sources of motivation.

When designing motivational instruments, policy makers also need to take into account the broader environment. Incentives usually target one aspect of behaviour, but they are introduced into a complex system with an existing set of cultures and constraints that may affect the willingness and ability of practitioners to respond as intended. This makes it difficult to predict the outcome of any intervention, or to generalise about the transferability of findings across systems. For example, in settings where governance is weak, or political will limited, incentives to improve provider performance have failed. Several studies have described incentive programmes that failed to reduce absenteeism because of officials' reluctance to fully implement the monitoring or incentive systems, ${ }^{6566}$ or politicians interfering with bureaucrat sanctions. ${ }^{67}$ This does not mean that incentives cannot work in some settings but that they require innovative solutions, such as finding trusted entities to hold providers accountable, such as peers or the broader community.

Technology could also provide new opportunities to address these challenges. Mobile technologies provide cheap and flexible solutions to improve information systems and feedback, support clinical decisions, facilitate and monitor delivery of care in remote settings, and eliminate many barriers to payment. ${ }^{68-70}$ Despite the enthusiasm around and potential of these tools, there have been few credible attempts at evaluating their capabilities to support and increase provider motivation. ${ }^{61}$

Contributors and sources: ML has studied the determinants of provider behaviour and quality of care in low and middle income countries, IP has studied policies for performance improvement in health systems, with a focus on high income countries. LH has much experience in public health research, particularly in child and maternal health, health systems and human resources in health.

Competing interests: We have read and understood BMJ policy on declaration of interests and have no relevant interests to declare.

Provenance and peer review: Commissioned; externally peer reviewed.

This article is part of a series commissioned by The $B M /$ based on an idea from the Harvard Global Health Institute. The BM/ retained full editorial control over external peer review, editing, and publication. Harvard Global Health Institute paid the open access fees.

Mylène Lagarde, associate professor of health economics

Luis Huicho, researcher ${ }^{2}$
Irene Papanicolas, associate professor of health economics $^{1}$

${ }^{1}$ Department of Health Policy, London School of Economics, London, UK

${ }^{2}$ Centro de Investigación en Salud Materna e Infantil and Centro de Investigación para el Desarrollo Integral y Sostenible, Universidad Peruana Cayetano Heredia, Lima, Peru

${ }^{3}$ Department of Health Policy and Management, Harvard TH Chan School of Public Health, Boston, MA, USA

Correspondence to: I Papanicolas

i.n.papanicolas@lse.ac.uk

\section{(2) (1) $\Theta$ OPEN ACCESS}

This is an Open Access article distributed in accordance with the Creative Commons Attribution Non Commercial (CC BY-NC 4.0) license, which permits others to distribute, remix, adapt, build upon this work non-commercially, and license their derivative works on different terms, provided the original work is properly cited and the use is non-commercial. See: http://creativecommons.org/ licenses/by-nc/4.0/.

\section{Check for updates}

1 Kruk ME, Larson E, Twum-Danso NA. Time for a quality revolution in global health. Lancet Glob Health 2016;4:e594-6. doi:10.1016/S2214. 109X(16)30131-0

2 Mohanan M, Vera-Hernández M, Das V, et al. The know-do gap in quality of health care for childhood diarrhea and pneumonia in rural India. JAMA Pediatr 2015;169:349-57. doi:10.1001/ jamapediatrics.2014.3445

3 Das J, Holla A, Mohpal A, Muralidharan K. Quality and accountability in healthcare delivery: auditstudy evidence from primary care in India. Am Econ Rev 2016;106:3765-99. doi:10.1257/ aer.20151138

4 Das J, Hammer J, Leonard K. The quality of medical advice in low-income countries. J Econ Perspect 2008;22:93-114. doi:10.1257/jep.22.2.93

5 National Academies of Sciences. Medicine. Crossing the global quality chasm: improving health care worldwide. National Academies Press, 2018.

6 Leonard KL, Masatu MC. Using the Hawthorne effect to examine the gap between a doctor's best possible practice and actual performance. J Dev Econ 2010;93:226-34. doi:10.1016/j. jdeveco.2009.11.001

7 Willis-Shattuck M, Bidwell P, Thomas S, et al. Improving motivation and retention of health professionals in developing countries: a systematic review. BMC Health Serv Res 2008;8:247. doi:10.1186/1472-6963-8-247

8 Hickam DH, Severance S, Feldstein A, et al. The effect of health care working conditions on patient safety. Evid Rep Technol Assess (Summ) 2003;74:1-3.

9 Aiken LH, Sloane DM, Bruyneel L, et al, RN4CAST consortium. Nurse staffing and education and hospital mortality in nine European countries: a retrospective observational study. Lancet 2014;383:1824-30. doi:10.1016/S01406736(13)62631-8

10 Das J, Woskie L, Rajbhandari R, Abbasi K, Jha A. Rethinking assumptions about delivery of healthcare: implications for universal health coverage. BMJ 2018;361:k1716. doi:10.1136/bmj.k1716

11 McGlynn EA, Asch SM, Adams J, et al. The quality of health care delivered to adults in the United States. N Engl I Med 2003;348:2635-45. doi:10.1056/ NEJMsa022615

12 Scott A, Sivey P, Ait Ouakrim D, et al. The effect of financial incentives on the quality of health care provided by primary care physicians. 
Cochrane Database Syst Rev 2011;9:CD008451. doi:10.1002/14651858.CD008451.pub2

13 Mendelson A, Kondo K, Damberg C, et al. The effects of pay-for-performance programs on health, health care use, and processes of care: a systematic review. Ann Intern Med 2017;166:341-53. doi:10.7326/ M16-1881

14 Witter S, Fretheim A, Kessy FL, Lindahl AK. Paying for performance to improve the delivery of health interventions in low- and middleincome countries. Cochrane Database Syst Rev 2012;2:CD007899. doi:10.1002/14651858. CD007899.pub2

15 Sherry TB, Bauhoff S, Mohanan M. Multitasking and heterogeneous treatment effects in pay-forperformance in health care: evidence from Rwanda. Am J Health Econ 2017;3:192-226. doi:10.1162/ AJHE_a_00072

16 Basinga P, Gertler PJ, Binagwaho A, Soucat AL, Sturdy J, Vermeersch CM. Effect on maternal and child health services in Rwanda of payment to primary health-care providers for performance: an impact evaluation. Lancet 2011;377:1421-8. doi:10.1016/ S0140-6736(11)60177-3

17 Gertler P, Vermeersch C. Using performance incentives to improve medical care productivity and health outcomes. NBER Working Paper No 19046. National Bureau of Economic Research, 2013.

18 Witter S, Fretheim A, Kessy FL, Lindahl AK. Paying for performance to improve the delivery of health interventions in low- and middleincome countries. Cochrane Database Syst Rev 2012;2:CD007899. doi:10.1002/14651858. CD007899.pub2

19 Currie J, Lin W, Meng J. Addressing antibiotic abuse in China: an experimental audit study. J Dev Econ 2014;110:39-51. doi:10.1016/j. jdeveco.2014.05.006

20 Papanicolas I, McGuire A. Do financial incentives trump clinical guidance? Hip replacement in England and Scotland. J Health Econ 2015;44:25-36. doi:10.1016/j.jhealeco.2015.08.001

21 Borghi J, Little R, Binyaruka P, Patouillard E, Kuwawenaruwa A. In Tanzania, the many costs of pay-for-performance leave open to debate whether the strategy is cost-effective. Health Aff(Millwood) 2015;34:406-14. doi:10.1377/ hlthaff.2014.0608

22 Braithwaite J, Churruca K, Ellis LA, et al. Complexity science in healthcare- aspirations, approaches, applications and accomplishments: a white paper. Australian Institute of Health Innovation, Macquarie University, 2017.

23 Eijkenaar F. Pay for performance in health care: an international overview of initiatives. Med Care Res Rev 2012;69:251-76. doi:10.1177/107755871143289

24 Van Herck P, De Smedt D, Annemans L, Remmen R, Rosenthal MB, Sermeus W. Systematic review: Effects design choices, and context of pay-for-performance in health care. BMC Health Serv Res 2010;10:247. doi:10.1186/1472-6963-10-247

25 Emanuel EJ, Ubel PA, Kessler JB, et al. USing behavioral economics to design physician incentives that deliver high-value care. Ann Intern Med 2016;164:114-9. doi:10.7326/M15-1330

26 Donato K, Miller G, Mohanan M, Truskinovsky Y, Vera-Hernandez M. Personality Traits and Performance Contracts: Evidence from a Field Experiment among Maternity Care Providers in India. Am Econ Rev 2017;107:506-10. doi:10.1257/aer. p20171105

27 Frey B. Not just for the money, an economic theory of personal motivation. Edward Elgar, 1997.

28 Berwick DM, James B, Coye MJ. Connections between quality measurement and improvement. Med Care 2003;41(Suppl):130-8. doi:10.1097/00005650-200301001-00004

29 Campanella P, Vukovic V, Parente P, Sulejmani A Ricciardi W, Specchia ML. The impact of public reporting on clinical outcomes: a systematic review and meta-analysis. BMC Health Serv Res 2016;16:296. doi:10.1186/s12913-016 1543-y

30 Lindenauer PK, Remus D, Roman S, et al. Public reporting and pay for performance in hospital quality improvement. N Engl J Med 2007;356:486-96. doi:10.1056/NEJMsa064964

31 Joynt KE, Orav EJ, Zheng J, Jha AK. Public reporting of mortality rates for hospitalized medicare patients and trends in mortality for reported conditions. Ann Intern Med 2016;165:153-60. doi:10.7326/M151462

32 Ryan AM, Nallamothu BK, Dimick JB. Medicare's public reporting initiative on hospital quality had modest or no impact on mortality from three key conditions. Health Aff (Millwood) 2012;31:585-92. doi:10.1377/hlthaff.2011.0719

33 Kolstad JT. Information and quality when motivation is intrinsic: evidence from surgeon report cards. Am Econ Rev 2013;103:2875-910. doi:10.1257/ aer.103.7.2875

34 Vallance AE, Fearnhead NS, Kuryba A, et al. Effect of public reporting of surgeons' outcomes on patient selection, "gaming," and mortality in colorectal cancer surgery in England: population based cohort study. BMJ 2018;361:k1581.

35 Blumenthal DM, Valsdottir LR, Zhao Y, et al. A survey of interventional cardiologists' attitudes and beliefs about public reporting of percutaneous coronary intervention. JAMA Cardiol 2018;3:629-34. doi:10.1001/jamacardio.2018.1095

36 Dranove D, Kessler D, McClellan M, et al. Is more information better? the effects of 'report cards' on health care providers. J Polit Econ 2003;111:555-88. doi:10.1086/374180

37 World Bank. World development report 2004: making services work for poor people. World Bank, 2003.

38 Bjorkman M, Svenson J. Power to the people: evidence from a randomised field experiment on community-based monitoring in Uganda. QJ Econ 2009;124:735-69. doi:10.1162/ qjec.2009.124.2.735

39 Devarajan S, Reinikka R. Making services work for poor people. World Bank, 2002.

40 Austin JM, Jha AK, Romano PS, et al. National hospital ratings systems share few common scores and may generate confusion instead of clarity. Health Aff (Millwood) 2015;34:423-30. doi:10.1377/ hlthaff.2014.0201

41 Delfgaauw J. Dedicated doctors: public and private provision of health care with altruistic physicians. Erasmus School of Economics, Erasmus Universiteit Rotterdam. Tinbergen Institute, 2007.

42 Arrow K. Uncertainty and the welfare economics of medical care. Am Econ Rev 1963;53:941-3.

43 Liu T. Ma C-tA. Health insurance, treatment plan, and delegation to altruistic physician. J Econ Behav Organ 2013;85:79-96. doi:10.1016/j. jebo.2012.11.002

44 Deci E, Ryan R. Intrinsic motivation and selfdetermination in human behavior. Springer, 1985. doi:10.1007/978-1-4899-2271-7

45 Patterson F, Knight A, Dowell J, Nicholson S, Cousans F, Cleland J. How effective are selection methods in medical education? A systematic review. Med Educ 2016;50:36-60. doi:10.1111/medu.12817

46 Lagarde M, Blaauw D. Pro-social preferences and self-selection into jobs: Evidence from South African nurses. J Econ Behav Organ 2014;107:136-52. doi:10.1016/j.jebo.2014.09.004.

47 Brock JM, Lange A, Leonard KL. Generosity norms and intrinsic motivation in health care provision: evidence from the laboratory and field. J Hum Resour 2016;51:133-62. doi:10.3368/ihr.51.1.133

48 Ashraf N, Bandiera O. Altruistic capital. Am Econ Rev 2017;107:70-5. doi:10.1257/aer.p20171097

49 Grobler L, Marais BJ, Mabunda SA, Marindi PN, Reuter H, Volmink J. Interventions for increasing the proportion of health professionals practising in rural and other underserved areas. Cochrane Database Syst Rev 2009;1:CD005314. doi:10.1002/14651858.CD005314.pub2

50 Lagarde M, Blaauw D, Cairns J. Cost-effectiveness analysis of human resources policy interventions to address the shortage of nurses in rural South Africa. Soc Sci Med 2012;75:801-6. doi:10.1016/j. socscimed.2012.05.005

51 Patterson F, Cleland J, Cousans F. Selection methods in healthcare professions: where are we now and where next?Adv Health Sci Educ Theory Pract 2017;22:22942. doi:10.1007/s10459-017-9752-7

52 Patterson F, Prescott-Clements L, Zibarras L, Edwards $\mathrm{H}$, Kerrin M, Cousans F. Recruiting for values in healthcare: a preliminary review of the evidence. Adv Health Sci Educ Theory Pract 2016;21:859-81. doi:10.1007/s10459-014-9579-4

53 Roy AD. Some thoughts on the distribution of earnings. Oxf Econ Pap 1951;3:135-46. doi:10.1093/oxfordjournals.oep.a041827

54 Besley T, Ghatak M. Competition and incentives with motivated agents. Am Econ Rev 2005:95:616-36. doi:10.1257/0002828054201413

55 Deserranno E. Financial incentives as signals: experimental evidence from the recruitment of village promoters in Uganda. Am Econ J Appl Econ 2019;11:277-317. doi:10.1257/ app. 20170670

56 Ashraf N, Bandiera O, Lee S. Losing prosociality in the quest for talent? Sorting, selection and productivity in the delivery of public services. Developmen discussion papers 65 . Suntory and Toyota International Centres for Economics and Related Disciplines, LSE, 2018.

57 Dal Bó E, Finan F, Rossi MA. Strengthening state capabilities: the role of financial incentives in the call to public service. Q J Econ 2013;128:1169-218. doi:10.1093/qje/qjt008

58 Schouten LMT, Hulscher MEJL, van Everdingen JJ, Huijsman R, Grol RP. Evidence for the impact of quality improvement collaboratives: systematic review. BMJ 2008;336:1491-4. doi:10.1136/ bmj.39570.749884.BE

59 Larsson S, Lawyer P, Garellick G, Lindahl B, Lundström $M$. Use of 13 disease registries in 5 countries demonstrates the potential to use outcome data to improve health care's value. Health Aff (Millwood) 2012;31:220-7. doi:10.1377/ hlthaff.2011.0762

60 Grant AM, Hofmann DA. It's not all about me: motivating hand hygiene among health care professionals by focusing on patients. Psychol Sci 2011;22:1494-9. doi:10.1177/0956797611419172

61 Lee S. Intrinsic incentives: a field experiment on leveraging intrinsic motivation in public service delivery. 2018. https://scholar.harvard.edu/files/lee/ files/scott_lee_intrinsic_incentives_latest.pdf

62 Herzberg F. One more time: how do you motivate employees? 1968. Harv Bus Rev 2003;81:87-96.

63 Maslow AH. A theory of human motivation. Psycho Rev 1943;50:370-96. doi:10.1037/h0054346

64 Maslow A. Motivation and personality. 3rd ed. Pearson Education, 1987

65 Dhaliwal I, Hanna R. The devil is in the details: the successes and limitations of bureaucratic reform in India. J Dev Econ 2017;124:1-21. doi:10.1016/j. jdeveco.2016.08.008

66 Banerjee AV, Glennerster R, Duflo E. Putting a band-aid on a corpse: incentives for nurses in the indian public health care system. J Eur Econ Assoc 2008;6:487-500. doi:10.1162 IEEA. 2008.6.2-3.487

67 Callen M, Gulzar S, Hasanain SA, et al. The political economy of public sector absence: experimental evidence from Pakistan. National Bureau of Economic Research Working Paper No 22340. NBER, 2016.

68 White A, Thomas DS, Ezeanochie N, Bull S. Health worker mhealth utilization: a systematic 
review. Comput Inform Nurs 2016:34:206-13. doi: $10.1097 / C I N .0000000000000231$

69 Lewis T, Synowiec C, Lagomarsino G, Schweitzer

J. E-health in low- and middle-income countries: findings from the Center for Health Market
Innovations. Bull World Health Organ 2012;90:33240. doi:10.2471/BLT.11.099820

70 Labrique AB, Vasudevan L, Kochi E, Fabricant R,

Mehl G. mHealth innovations as health system

strengthening tools: 12 common applications and a visual framework. Glob Health Sci Pract 2013:1:160-

71. doi:10.9745/GHSP-D-13-00031

Cite this as: $B M$ J 2019;366:15210

http://dx.doi.org/10.1136/bmj.15210 